\title{
A Novel Propulsion System Based on Cycloidal Rotors coupled with Pair-wing for VTOL Aircrafts; Cyclo-Craft
}

\author{
$1^{\text {st }}$ Mehdi Habibnia \\ Center for Mechanical and Aerospace Science and Technologies \\ University of Beira Interior \\ covilha, Portugal \\ m.habibnia.rami@gmail.com \\ $2^{\text {nd }}$ Frederico Rodrigues \\ Center for Mechanical and Aerospace Science and Technologies \\ University of Beira Interior \\ Covilha, Portugal \\ fredmfr@hotmail.com
}

\author{
$3^{\text {rd }}$ Jose Carlos Pascoa \\ Center for Mechanical and Aerospace Science and Technologies \\ University of Beira Interior \\ Covilha, Portugal \\ pascoa@ubi.pt
}

\begin{abstract}
Aircraft with the capabilities of hovering and Vertical Take-off and Landing (VTOL) are increasing for various applications. Carrying payloads, controlling cameras and surveillance, critical missions like firefighters, payload carrying from non-terrain regions like forests with high demanding of maneuverability and such environmental circumstances are of examples for the mentioned aircraft types. Although helicopters are typically the most famous crafts of these types, other designs are already available as alternatives, whereas each specific design can be selected according to the expectations. Cycloidal rotor (cyclorotor) has recently been potentially proposed for propulsion system in VTOL aircraft. Higher maneuverability, less noise pollution and more stable flights are some advantageous of the stated systems compared with those of screw propellers employed in helicopters. The present work illustrates a novel conceptual design of a VTOL propulsion system consisting two cycloidal rotors combined with pair-wings which is submitted as an international patent. The downwash jet releasing from the front cyclorotor is partially being processed through the pair-wings towards the rear rotor. The wings are capable of being adjusted for enhanced flow control. Being capable of VTOL from both ground and marine surfaces is the other significant characteristic of the proposed propulsion system. Plasma actuators are employed on pair-wing in order to further enhance the efficiency as an advanced flow control technique. Both numerical and experimental results are presented to further clarify this novel propulsion mechanism.
\end{abstract}

Index Terms-Cyclo-craft, Cycloidal rotor, VTOL aircraft, OpenFOAM, Plasma.

PT2020 - CENTRO2020 - EMaDeS - ERDF European Union.

\section{INTRODUCTION}

Vertical take off and landing (VTOL) is termed to the aircraft that is capable of vertical take-off and landing and also forward cruise speeds [1]. According to the numerous operational advantageous of these aircraft types, they are increasingly utilized for various missions where we are in short terrains for the VTOL phases. Depending on the main purpose of the aircraft, there have been several operating types designed over years. Conventional helicopters using screw propellers are of the most well-known VTOL crafts. The principal difference of the different VTOL aircraft are mostly regarded to their propulsion systems in order to provide VTOL phases of flight. Cycloidal rotor is one of the multi-bladed systems which has been studied since a century [2]. Tugboats and sub-marines in naval thrusters, wind turbines in power and energy industry, and airships and aerial crafts in aerospace branch are some of the applications of cycloidal rotors [3]. Since the initial report of cyclorotor usage from Kirsten-Boeing in 1926 [4], more designs of aircraft with this system as propulsion device in projects like ACROSTAT [5], MAAT [6], CROP [7], BOSCH and IAT21 were further investigated.

Yun et al. [8] studied an unmanned aerial vehicle (UAV) operating with cycloidal rotor in both numerical and experimental 


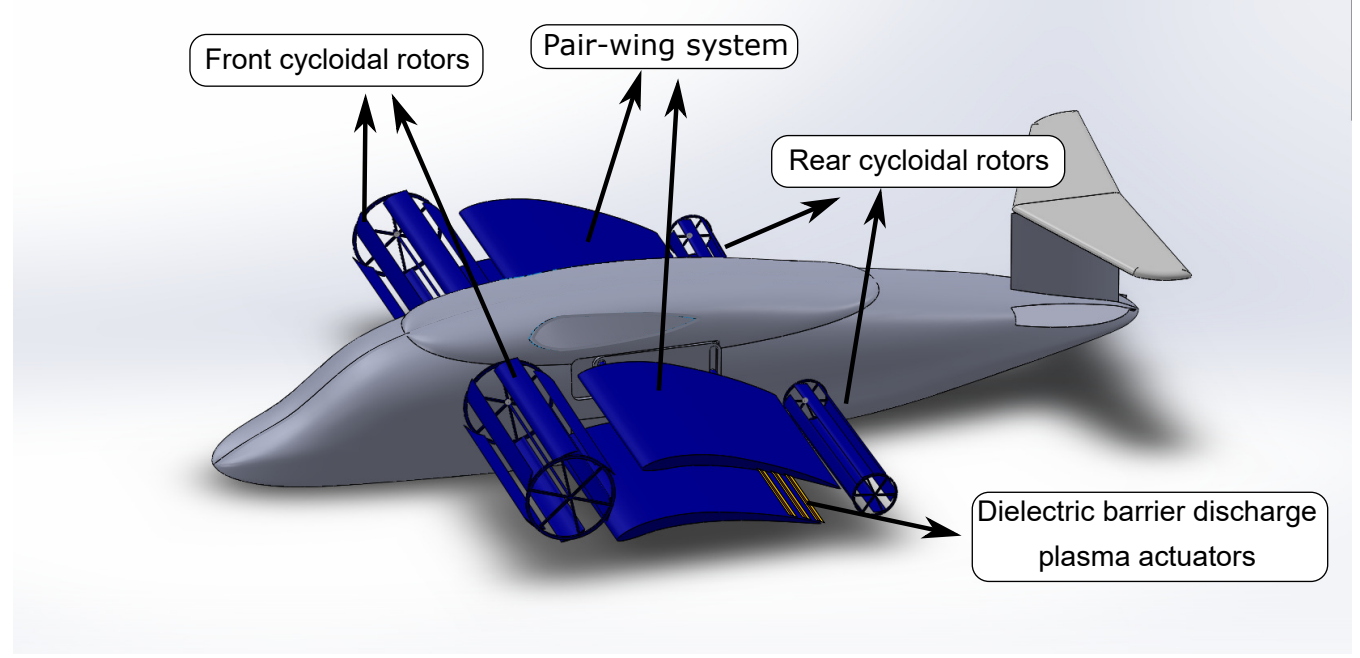

Fig. 1. A schematic of the cyclo-craft with two cycloidal rotors and the pair-wing proposed for VTOL propulsion system .

approaches. In micro air vehicles (MAV), Benedict et al. [9] conducted extensive numerical and experimental tests in order to higher efficiency achievements in flights. They successfully launched cyclorotor on a 290 gram micro-scale aerial craft with appreciable flight and control capabilities [10]. Rami and Pascoa [11] studied the ground effect on the performance and efficiency of the cyclorotor on an UAV-scale aircraft in takeoff or landing phase. In a complementary survey, Habibnia and Pascoa [12] proposed active control of pitching oscillations of the blades using artificial intelligence and neural network analysis. They stated that usign active control method, higher performances are achievable. Aerodynamic operation analysis for cyclorotor-thruster crafts at hovering state was the issue which was investigated both numerically and analytically by Leger et al. [14].

In further improving the cyclorotor efficiency, Xisto et al. [13], [29] performed plasma enhanced blades with the aim of enhanced aerodynamic characteristics. In fact, they implemented dielectric barrier discharge (DBD) plasma actuators on blade surfaces in order to gain higher control on the flow over the rotating-oscillating blades in cycloidal rotor. DBD plasma actuators have been widely proposed to be manipulated for flow controls, separation and flow loss prevention and many other applications in mechanical and aerospace engineering over decades [15]-[18]. Plasma actuators are highly featured for their precise and rapid responses, extra-low weight, quite simple implementation and their robustness [19]-[22]. DBDs construct three layers with 2 electrodes and one separating dielectric layer in the middle. As the device functions, an electric field configures which ionize the air, then, a generated body force accelerates the ionic charged particles [23], [24].

In the present paper, A new propulsion design for a VTOL aircraft (Cyclo-craft) is introduced. The system is comprised of two cycloidal rotors combined with pair-wing in between the rotors. Each of these combinations will be launched at both sides of the aircraft. The main concept of the mentioned device is to get the most advantage from the downwash jet flow from the cyclorotor rather than releasing it away. The pair-wing structure in the middle of the two rotors acts as a nozzle vane that guides the flow towards the rear cyclorotor. To be mentioned that the front cycloidal rotor is in a bigger scale than the rear one. This new concept is already passing the international patent considerations as a novel propulsion system for VTOL aircraft.

The plasma actuators are utilized on the surfaces of the wings for better flow control and avoidance of flow losses. One of the main reasons can be to prevent the boundary/shear layer separation while the flow is approaching to the trailing edge of the wings [25], [26]. In this work, the operating mechanism of the proposed propulsion system is studied both numerically and experimentally. Firstly, the system model is undergone through computational fluid dynamics (CFD) approach to further study the flow mechanism and performance evaluation. The other phase of the current study is to experimentally test a multi-DBD plasma fabricated system on the pair-wing assembly. Further illustrations are accordingly explained and discussed in the subsequent sections.

\section{CyClo-CRAft Design}

The proposed propulsion system for VTOL aircraft is a set of consecutive devices with which all are technically influential on each other. This design is basically one of the rare or first structures where it gain advantage from the cyclorotor flow for further thrust production in a system. As is schematically depicted in Fig. 1, the front cycloidal rotor is considered bigger in rotor and blade size compared with the rear rotor. In the frontal portion of the system, it is intended to get higher amount of flow stream involved through the system. As will be further explained in subsequent simulations, the downwash jet flow from a cyclorotor gets an inclination 
when passed out from the bottom-half of the rotor. Imposing counter-clock wise rotational direction for both cyclorotors, their downwash will shift rightward, which is the reason of designating the pair-wing right after the front cycloidal rotor. This in fact is to pull a portion of the downwash flow inside the pair-wing vane, and eventually passing it to the rear cyclorotor.

However, to avoid flow separations, and also to further damp the turbulent intensity of the passing flow through the nozzle-shape vane, DBD plasma actuators are proposed as efficient devices to be implemented on the wing surfaces. The experimental tests on applying plasma is discussed later in its specific section. The rear cyclorotor, as shown in Fig. 1, is positioned closely after the pair-wing exit patch. Smaller size of this rotor compared with the front one, and the forward flow streaming towards the rear rotor gives the opportunity of running it in comparatively higher rotational speeds.

Cycloidal rotor were also determined to reveal high maneuverability, low noise production and stable hovering phase as a thruster for VTOL aircraft. On the other side, the rear cyclorotor in the current design can be altered laterally with the origin of the attached point from the craft. This functionality provides high control and fast direction shift of the aircraft since it changes the thrust vector produced by rear cyclorotor. In addition, the proposed propulsion mechanism is also able to perform VTOL from both marine and ground surfaces.

\section{NUMERICAL Simulation}

\section{A. OpenFOAM Framework}

The current CFD simulations are fully conducted using OpenFOAM toolbox. PimpleDyMFoam solver is appropriately chosen for the numerical approach. The optimum turbulence model for the present cycloidal rotor simulations is $k-\omega-S S T$ which was recommended [12], [27], [28] for rotational and sensitive flows. The 2 dimensional computational consists of $200 K$ cells for the coarse and $300 K$ for fine mesh. For all displacing (rotating and oscillating) zones, cyclicAMI technique is used for the overlapping interfaces. The grids are full structured in the whole domain which are completely performed within OpenFOAM using blockMesh and snappyHexMesh utilities.

\section{B. Code Validation}

For the validation of the CFD results with the experiment [8] for cycloidal rotor operation, power loading (P.L) is used for the comparisons. The experimental results and CFD results for different operating conditions and both grids are presented in Fig.2. Grid comparisons are shown for pitch angles of $20^{\circ}$ and $30^{\circ}$ at 5 different rotating speeds. All the blade profiles are with NACA0012 airfoils. The front and rear rotors are 0.8 and $0.6 \mathrm{~m}$ in diameter, respectively. In the current simulations, the front cyclorotor operates at 400,500, $600 R P M$ with constant $35^{\circ}$ pitching oscillation, whereas the same parameters for the rear rotor are $700,800,900 R P M$ with $25^{\circ}$, respectively. It should be noted that the rotations are happening in order, meaning that while the front runs at 400 , the rear runs at 700 $R P M$.

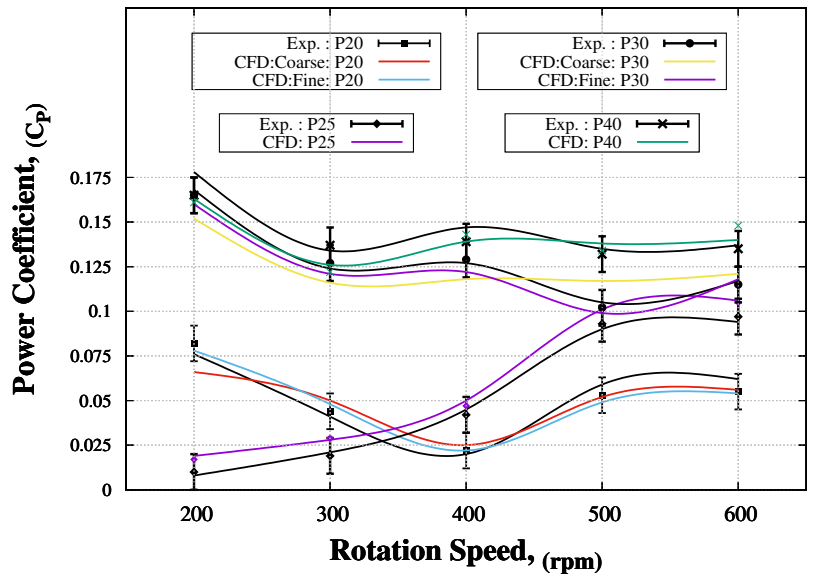

Fig. 2. Power loading coefficient comparison for different operating conditions and grid structures between CFD and experiment results.

\section{EXPERIMENTAL SETUP}

To analyse the flow behavior in the pair-wing system of the aircraft flow visualization measurements and Pitot tube measurements were conducted. The experimental setup used is shown in figure 4.

The DBD plasma actuators were fabricated with Kapton as dielectric layer and copper tape as electrodes. The electrodes presented $80 \mu \mathrm{m}$ thickness and $80 \mathrm{~mm}$ length. The exposed electrode presented a width of $5 \mathrm{~mm}$ thickness while the embedded electrode presented a width of $15 \mathrm{~mm}$. The dielectric layer presented a thickness of $1.02 \mathrm{~mm}$, a width of $50 \mathrm{~mm}$ and a length of $100 \mathrm{~mm}$. The DBD plasma actuators were supplied by an high voltage power source, model PVM 500, which allows to produce voltages up to $20 \mathrm{kV}$ AC peak-topeak with frequencies within the range of $20 \mathrm{kHz}$ to $50 \mathrm{kHz}$. The input signal was monitored by a digital oscilloscope model PicoScope $5443 \mathrm{~A}$ connected with an high voltage probe. The DBD plasma actuators were implemented in the top surface of the bottom wing as shown in figure 4 .

The pair-wing system was constituted by two NACA 0012 airfoils with a chord length of around $190 \mathrm{~mm}$. Considering the complexity of cycloidal rotor thrusters, the inlet flow of the pair-wing system was provided by an axial fan model HET EDF 6904 powered by a brushless motor Typhoon EDF. The brushless motor rotation speed was controlled by means of an electronic speed controller, model $80 A-E c o-6 S E S C$, connected to a pulse-width modulation (PWM) pulse generator, model PWM Hobbyking LED Servo Tester. This axial fan allows to achieve velocities up to $30000 \mathrm{rpm}$. The axial fan was supplied by a power source model Puls $S L 30$, which is able to provide $24 V$ or $28 V$ DC with a current up to $30 \mathrm{~A}$. The flow visualization images were captured by a digital camera CCD "C10600 - 10BOrca - R2" which presents a resolution of $1344 \times 1024$. A smoke generator, model Crenova FM-02, with a power of $400 \mathrm{~W}$, was 


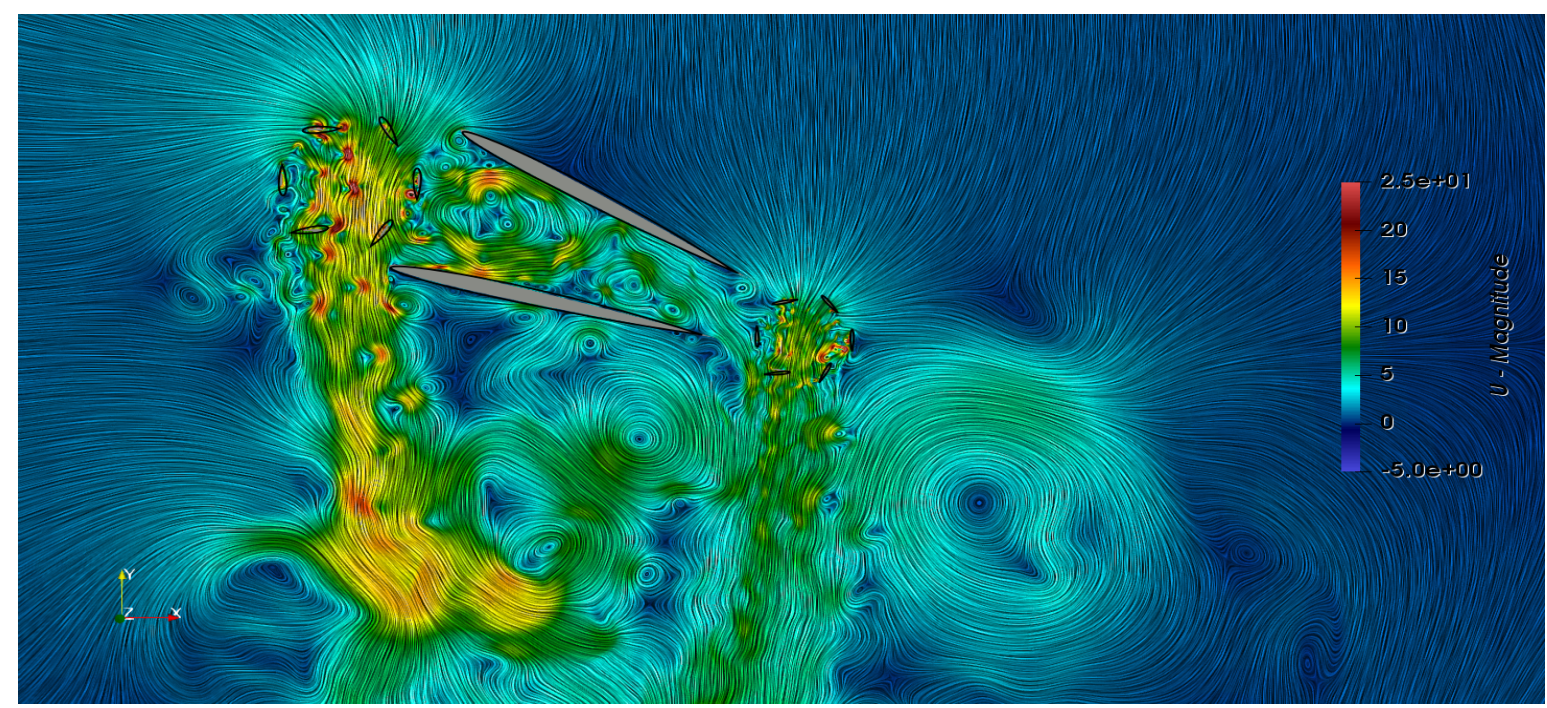

Fig. 3. Flow velocity contour of the propulsion mechanism at hover-state operation of the cycloidal rotors.

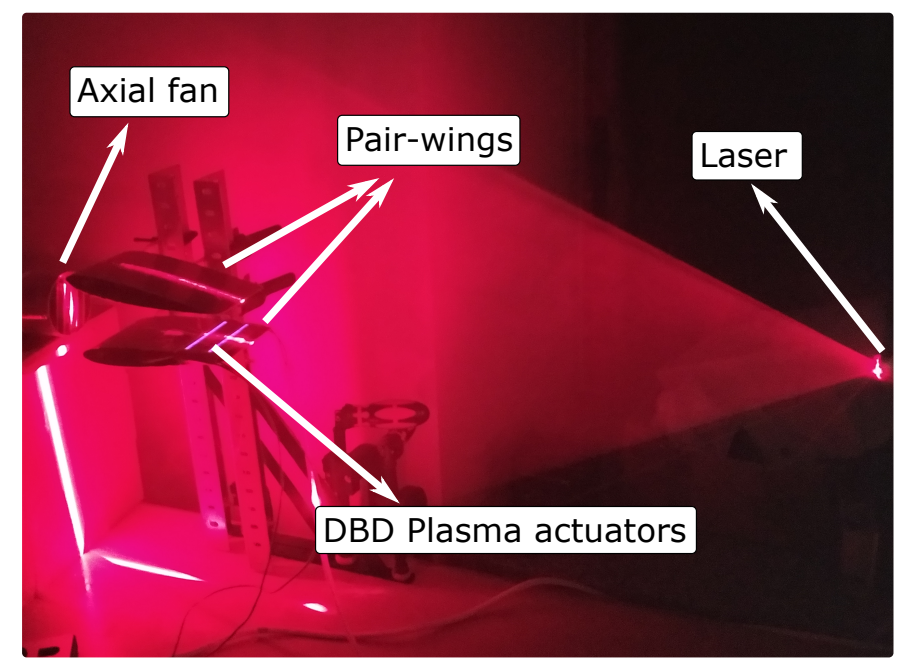

Fig. 4. Experimental facilities.

used to mark the flow which was illuminated by a laser system model 1 L2S - SL-660-130-S-A-60 SteamLine Laser System. Velocity measurements were performed by using a stainless steel Pitot tube, model "167-6" coupled to a micromanometer, model Extech HD 350. This micro-manometer presents a resolution of $0.01 \mathrm{~m} / \mathrm{s}$, an accuracy of $1 \% F S$ and it provides a data live streaming to the computer.

\section{RESULTS AND DISCUSSION}

\section{A. CFD Simulations}

The current numerical simulations for the proposed VTOL propulsion system are run for the hovering phase with null velocity. Technically, the desirable condition is to guide a portion of downwash jet from the front cyclorotor toward the pair-wing vane. The downwash jet velocity is relatively high according to the rotating speed of the rotor, hence, the attempts are to avoid full release of this flow to dissipate without extracting the maximum energy from it. This fact facilitates the operation of the rear cyclorotor to comparatively higher angular velocities rather than operating with no induced flow. The entering flow from the pair-wing nozzle vane to the rear rotor provides forward flight state for this rotor as well. The flow velocity contour is depicted in Fig. 3 for 500 and $800 R P M$ rotational speeds for the front and rear cyclorotors, respectively. The mid-wings length are both equal and $1.45 \mathrm{~m}$, but each of them are differently positioned and inclined. As is shown, the pro-

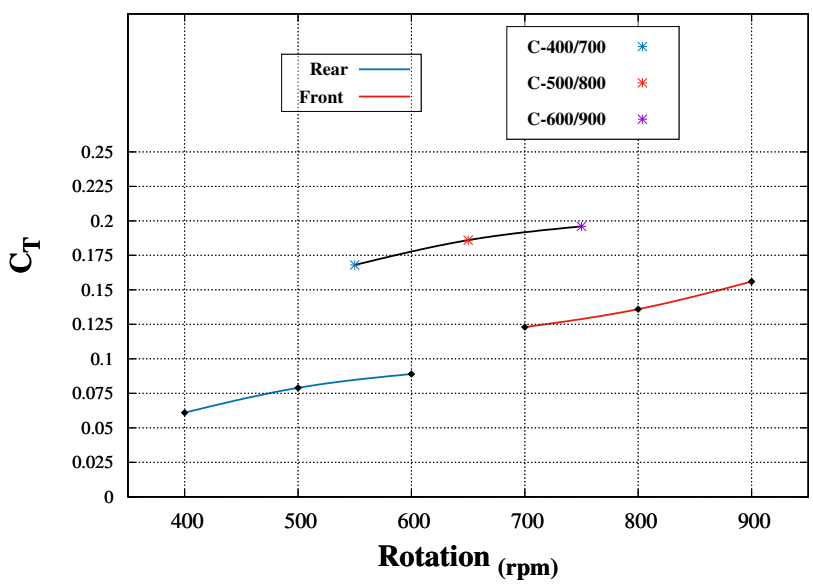

Fig. 5. Thrust coefficient comparisons for both rotors in single and the coupled cyclo-craft system under different rotational speeds.

posed design is capable of providing the flow functionality as was expected. The downwash jet flow from the front cyclorotor is shedding rightward as a result of $\mathrm{CCW}$ rotational direction. This jet flow splits in two portions as it reaches the pairwing section. The combination of the cycloidal rotors and the wings in this propulsion mechanism resulted in a considerable higher thrust productions compared with a single-cycloidal 


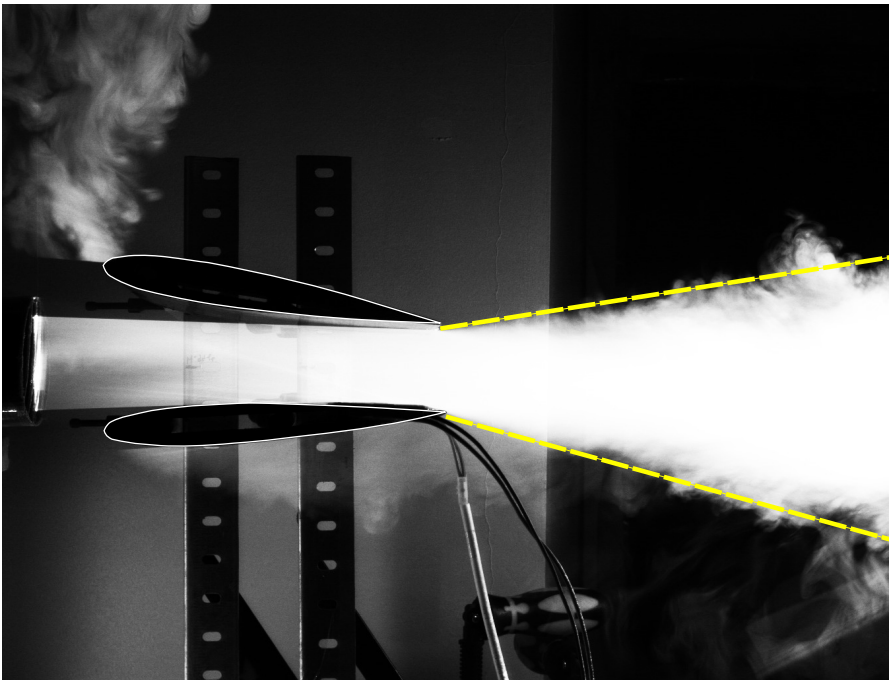

(a) Straight jet flow with plasma actuation off.

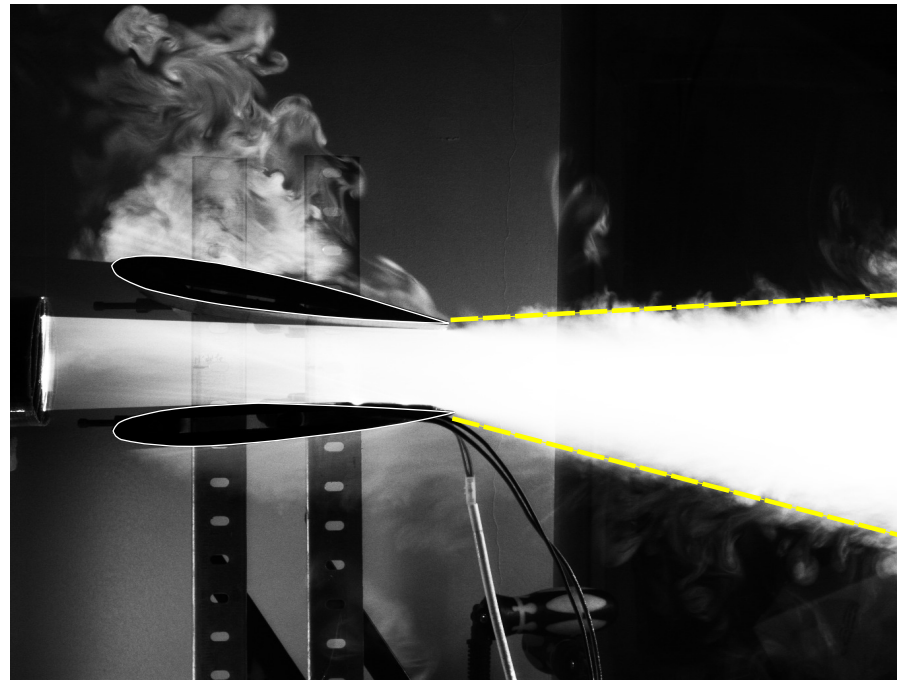

(b) Straight jet flow with plasma actuation on.

Fig. 6. Flow jet behavior with and without plasma actuation.

rotor thrusters studied for UAV size VTOL aircraft. The plots of the thrust coefficients for each of the cyclorotors (front and rear) individually, and the proposed combined propulsion mechanism is shown in Fig.5. The comparisons reveal a higher thrusting performance of the cyclo-craft mechanism than those of single operating cycloidal rotors. This figure shows thrust coefficients for cycloidal rotors with front and rear ones size and operating conditions with red and blue, respectively. This means the a cycloidal rotor with diameter of $0.8 \mathrm{~m}$ and $35^{\circ}$ pitch angle for the front and one with $0.6 \mathrm{~m}$ and $25^{\circ}$ for the rear cyclorotor are separately calculated. The front rotor were analyzed at the 3 last rotational speeds and the first 3 values $(400,500$ and 600) are set for the rear rotor. For the proposed cyclo-craft, a combination of 3 different sets of rotating speeds are considered. For instance, 400/700 regards to a combination of operating at 400 and $700 R P M$ for the front and rear cyclorotors, respectively. It is shown that the thrusting performance has increased considerably compared with the individually running cyclorotors.

\section{B. Experimental Tests}

The pair-wing system was experimentally tested for an inlet height section of $8 \mathrm{~cm}$ and an outlet height section of $5 \mathrm{~cm}$, which means a decrease ratio of 0.625 from the inlet to the outlet. The flow visualization images obtained with and without plasma actuation are presented in figure 6 .

In figures 6 we present the flow visualization images obtained with the wings positioned for a straight jet flow. The plasma actuators were supplied with a voltage of $10 \mathrm{kVpp}$ and a frequency of $24 \mathrm{kHz}$. In the flow visualization images, two tangent lines to the top and bottom limits of the flow were drawn. At a first look, the plasma actuation effect is not evident but with the help of these lines we see that the flow has a tendency to attach more to the bottom wing. This effect is not that evident because the pair-wing system works as nozzle whose section area is reduced from the outlet to the inlet. Therefore, there is no flow separation in the bottom wing and the plasma actuation effect is reduced. However, to confirm the plasma actuation effect on the flow velocity field, Pitot tube velocity measurements were performed at the outlet of the system. Notice that the Pitot tube has a diameter of $3 \mathrm{~mm}$ thus, the point zero, it actually corresponds to a distance of $1.5 \mathrm{~mm}$ from the wall. Figure 7 shows the velocity results obtained with an without plasma actuation.

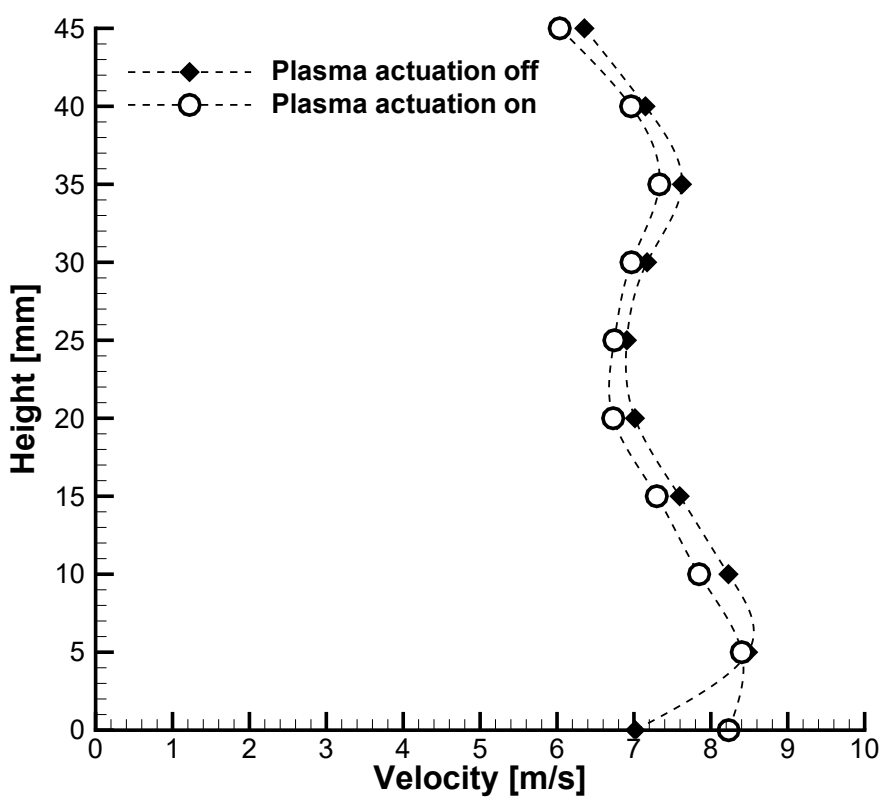

Fig. 7. Velocity profiles at the pair-wing outlet.

Figure 7 shows that the velocity near to the top surface of the bottom wing increases significantly when the plasma actuators are on. We can see that the velocity in this region is approximately $1.25 \mathrm{~m} / \mathrm{s}$ higher when the plasma actuation is 
operating. Therefore, we may conclude that when the plasma actuators are turned on, the flow is attached to the surface where they are applied and the flow velocity in this region increases. Due to that, in the regions above the flow velocity slightly decreases since the main flow is slightly displaced to the bottom region. We may conclude that the use of plasma actuation in the pair-wing system may be useful to control the output jet direction and also to reduce the flow losses in the system.

\section{CONCLUSION}

A novel propulsion system for VTOL capable aircraft is demonstrated in the present work. The presented mechanism (cyclo-craft), is based on two cycloidal rotors (front and rear), and a pair-wing settled between the two rotors. The current study includes both CFD simulations and experimental tests for the presented system. The numerical study is more specified to the operating flowfield through the system from the front downwash jet to the rear cyclorotor. The CFD results revealed higher thrusting performance of the proposed propulsion system. The other phase of the current study relates to the experimental evaluations of the presence of DBD plasma actuators on the wing surfaces. Plasma implementation also showed flow enhancement while passing the pair-wing passage toward the rear cyclorotor.

\section{ACKNOWLEDGMENT}

This paper is mainly supported by the project Centro-010145-FEDER-000017 - EMaDeS - Energy, Materials and Sustainable Development, co-financed by the Portugal 2020 Program (PT2020), within the Regional Operational Program of the Center (CENTRO2020) and the European Union through the European Regional Development Fund (ERDF). Authors also wish to thank the support from European Union project of Cycloidal Rotor for Optimized and Propulsion (CROP) within the 7th Framework Programme under grant number 323047. This work was carried on in C-MAST - Center for Mechanical and Aerospace Sciences and Technologies, Research Unit No.151.

\section{REFERENCES}

[1] McCormick, Barnes Warnock, "Aerodynamics of V/STOL flight,". Courier Corporation, 1999.

[2] Boirum, Curtis, and Scott Post. "Review of historic and modern cyclogyro design," 45th AIAA/ASME/SAE/ASEE Joint Propulsion Conference and Exhibit. 2009.

[3] Ilieva, Galina, et al. "A critical review of propulsion concepts for modern airships," Open Engineering 2.2 (2012): 189-200.

[4] Sachse, H. "Kirsten-Boeing propeller," (1926).

[5] Onda, Masahiko, and Yasushi Morikawa. "An acrobatic airship 'Acrostat'," SAE transactions (1991): 2101-2105.

[6] Ilieva, Galina, et al. "MAAT-Promising innovative design and green propulsive concept for future airship's transport," Aerospace science and technology 35 (2014): 1-14.

[7] "CROP Report - European Commission FP7,"

[8] C. Y. Yun, I. K. Park, H. Y. Lee, J. S. Jung, I. S. Hwang, S. J. Kim, "Design of a new unmanned aerial vehicle cyclocopter," Journal of the American Helicopter Society 52 (1) (2007) 24-35

[9] Benedict,M.,Shrestha,E.,Hrishikeshavan,V.,and Chopra,I., "Development of a micro twin-rotor cyclocopter capable of autonomous hover," Journal of Aircraft, Vol.51, No.2, 2014, pp.672-676.
[10] Benedict,M.,Ramasamy,M.,Chopra,I.,andLeishman,J.G., "Performance of a cycloidal rotor concept for micro air vehicle applications," Journal of the American Helicopter Society, Vol.55, No.2, 2010, pp.22002-22002.

[11] Rami, M. H., and Pascoa, J., 2019. "Numerical analysis of a cycloidal rotor under diverse operating conditions and altitudes," In SAE Technical Paper Series, SAE International.

[12] Habibnia, M., and Pascoa, J., 2019. "ANN assisted flow modeling and analysis for a cyclorotor in ground effect," Aerospace Science and Technology, 95, dec, p. 105495.

[13] Xisto, C. M., P'ascoa, J. C., Abdollahzadeh, M., Leger, J. A., Schwaiger, M., Wills, D., Masarati, P., and Gagon, L., 2014. "PECyT - plasma enhanced cycloidal thruster," In50thAIAA/ASME/SAE/ASEE Joint Propulsion Conference, American Institute of Aeronautics and Astronautics.

[14] Leger,J.A.,P' ascoa,J.C.,andXisto,C.M.,2015. "Analytical modeling of a cyclorotor in hovering state," Proceedings of the Institution of Mechanical Engineers, Part G: Journal of Aerospace Engineering, 229(12),feb,pp.2163- 2177.

[15] Rodrigues, F. F., Mushyam, A., Pascoa, J. C., and Trancossi, M., 2019. "A new plasma actuator configuration for improved efficiency: the stair shaped dielectric barrier discharge (SSDBD) actuator," Journal of Physics D: Applied Physics, may.

[16] Mushyam, A., Rodrigues, F., and Pascoa, J. C., 2019. "A plasma-fluid model for EHD flow in DBD actuators and experimental validation," International Journal for Numerical Methods in Fluids, 90(3), jan, pp. 115-139.

[17] Abdollahzadeh,M.,Pascoa,J.,and Oliveira,P.,2016. "Implementation of the classical plasma-fluid model for simulation of dielectric barrier discharge (dbd) actuators in openfoam," Computers and Fluids, 128, pp. 77-90.

[18] Abdollahzadeh, M., Pascoa, J. C., and Oliveira, P. J., 2014. "Modified split-potential model for modeling the effect of dbd plasma actuators in high altitude flow control,' Current Applied Physics, 14, pp. 1160-1170.

[19] Abdollahzadeh, M., Pascoa, J. C., and Oliveira, P. J., 2014. "Twodimensional numerical modeling of interaction of micro-shock wave generated by nanosecond plasma actuators and transonic flow," Journal of Computational and Applied Mathematics, 270, nov, pp. 401-416.

[20] Rodrigues, F. F., Pascoa, J. C., and Trancossi, M., 2018. "Experimental analysis of alternative dielectric materials for DBD plasma actuators," In Volume 1: Advances in Aerospace Technology, ASME.

[21] Rodrigues, F. F., Pascoa, J. C., and Trancossi, M., 2018. "Experimental analysis of dielectric barrier discharge plasma actuators thermal characteristics under external flow influence," Journal of Heat Transfer, 140(10), may.

[22] Rodrigues, F. F., Pascoa, J. C., and Trancossi, M., 2017. "Experimental thermal characterization of DBD plasma actuators," In Volume 1: Advances in Aerospace Technology, American Society of Mechanical Engineers.

[23] Pendar,M.-R.,and Pascoa,J.C.,2019. "Numerical modeling of electrostatic spray painting transfer processes in rotary bell cup for automotive painting," International Journal of Heat and Fluid Flow, 80, dec, p. 108499.

[24] Pendar, M. R., and Pascoa, J., 2019. "Numerical investigation of electrostatic spray painting transfer processes for vehicle coating," In SAE Technical Paper Series, SAE International.

[25] Rami, M. H., Shidvash Vakilipour, Sabour, M. H., Riazi, R., and Hassannia, H., 2019. "Shear layer investigation through a high-load cascade in low-pressure gas turbine conditions," International Journal of Mechanical and Mechatronics Engineering.

[26] Vakilipour, S., Habibnia, M., Sabour, M. H., Riazi, R., and Mohammadi,M.,2017. "Surface pressure characteristics of a highly loaded turbine blade at design and off-design conditions a CFD methodology," Thermophysics and Aeromechanics, 24(3), may, pp. 469-482.

[27] M. R. Pendar, E. Roohi, Detailed investigation of cavitation and super cavitation around different geometries using various turbulence and mass transfer models, in: Journal of Physics: Conference Series, Vol. 656, IOP Publishing, 2015, p. 012070.

[28] A. Kolahan, E. Roohi, M.-R. Pendar, Wavelet analysis and frequency spectrum of cloud cavitation around a sphere, Ocean Engineering 182 (2019)

[29] Xisto, Carlos M., et al., Numerical Modeling of Geometrical Effects in the Performance of Cycloidal Rotor, 11th World Conference on Computational Mechanics, No. p1848, 2014. 